\title{
A universidade deve patentear suas invenções?*
}

\author{
Luciano Martins Costa Póvoa \\ Universidade de Brasília (UnB)
}

Recebido: 02/04/2009 Versão revisada (entregue): 24/03/2010 Aprovado: 31/03/2010

\section{RESUMO}

Este artigo discute se a universidade deve patentear ou não suas invenções, com base na análise da lógica da produção científica, nas críticas apontadas na literatura e nos resultados de um survey sobre a transferência de tecnologia de universidades e institutos públicos de pesquisa no Brasil, realizado a partir dos dados do Diretório de Grupos de Pesquisa no Brasil - CNPq, censo de 2004. Dessas análises é apontada a existência de um complexo trade-off entre a divulgação científica com o livre acesso para desenvolvê-la e a agilização do processo de comercialização das invenções. Como solução para esse trade-off é argumentado que tal problema deve ser abordado questionando-se "como" a universidade deve patentear em vez de "se deve" patentear ou não. A resposta sugerida passa pela formulação dos contratos de licenciamento. É desejável, do ponto de vista do bem-estar da sociedade, que a universidade tente licenciar suas tecnologias sem exclusividade, para garantir que a invenção esteja disponível ao máximo possível de interessados. Somente no caso de esse tipo de licenciamento não encontrar interessados, a universidade deveria oferecer um contrato de exclusividade. Também seria desejável que as universidades concedessem uma "licença para pesquisa” a pesquisadores

O autor agradece à Fundação de Amparo à Pesquisa de Minas Gerais - Fapemig e à Capes, pelo apoio recebido para a elaboração deste trabalho, bem como aos pareceristas anônimos da revista e aos professores Eduardo Albuquerque, Jorge Britto, Renato Garcia, Ruben Sinisterra Millán e Wilson Suzigan, pelos comentários e sugestôes. Os erros remanescentes são de inteira responsabilidade do autor. 
que pretendem usar o conhecimento protegido pelas patentes com a finalidade de promover o avanço da pesquisa científica.

Palavras-Chave | Patente; Universidade; Ciência.

Códigos JEL | 030; 034

\section{Should Universities Patent their Inventions?}

\section{ABSTRACT}

This paper discusses the question: should universities patent their inventions or should not? The question is analyzed through the lens of the logic of the scientific production. It is also considered the critiques pointed in the literature and presented and discussed the results of an original survey on technology transfer from universities and public labs to firms in Brazil. It is discussed the existence of a trade-off between the free access to new scientific knowledge and the agility of university's inventions commercialization. It is argued that the question should be "how" should universities patent their inventions instead of "should or not". From the society welfare point-of-view, universities should try licensing without exclusivity in order to assure that the invention reach the highest number of firms interested in the development of the invention. It would be desirable to concede research excuses for those interested in the use of university patents for scientific research purposes.

KEYWORDS | Patent, university, science

JEL-CODES $\mid$ 030; 034

\section{Introdução}

Patentear invenções financiadas por recursos públicos parece ser uma contradição, afinal, os contribuintes já estão pagando para que conhecimentos sejam criados e gerem benefícios para a sociedade. Entre os contribuintes estão as empresas, que terão que licenciar patentes para desenvolver comercialmente as invenções acadêmicas às quais teriam acesso livre se o conhecimento não fosse patenteado. Por 
outro lado, argumenta-se que essas invenções têm maior probabilidade de chegar ao mercado se forem patenteadas. Um dos principais exemplos da aplicação desse último argumento é o Bayh-Dole Act, aprovado em 1980 nos EUA, que buscou incentivar a comercialização de descobertas acadêmicas, ao facilitar o processo de obtenção de patentes resultantes de pesquisas financiadas por fundos federais e sua comercialização por parte das universidades.

Segundo os proponentes do Bayh-Dole Act, os direitos de propriedade intelectual das universidades, licenciados de forma exclusiva, serviriam de estímulos para empresas realizarem investimentos em pesquisas subsequentes para gerar uma inovação, contribuindo para a transferência de conhecimentos tecnológicos para a indústria (MAZZOLENI, 2005; SAMPAT, 2006). De acordo com Mowery et al. (2004, p. 6), a discussão e a aprovação do Bayh-Dole Act, em grande medida, tiveram como base "(...) a crença de que patentear era tanto necessário quanto suficiente para facilitar a transferência das invenções acadêmicas para o desenvolvimento industrial e comercial". (tradução nossa). Entretanto, os autores destacam que, em muitos casos, a patente não é necessária para transferência e comercialização da tecnologia, servindo apenas para gerar receita para a universidade e, além disso, pode dificultar a difusão da invenção e do uso do conhecimento tecnológico por trás da invenção patenteada, caso as políticas de licenciamento das universidades sejam demasiadamente restritivas.

O tema "patentes de universidades" envolve uma série de controvérsias. $\mathrm{O}$ objetivo deste artigo é apresentar as principais questôes debatidas na literatura que se concentram na análise do contexto dos países desenvolvidos, em especial dos EUA - e discuti-las considerando, de forma breve, o contexto brasileiro. Os resultados de um survey conduzido pelo autor (PÓVOA, 2008) e os argumentos apresentados na literatura sobre os efeitos das patentes no bem-estar da sociedade servem como fio condutor para avaliar a pergunta que este artigo se propóe a responder: a universidade deve patentear suas invenções?

Parece ponto pacífico a ideia de que a maior parte da comunidade acadêmica concorda quanto à livre divulgação dos resultados de suas pesquisas. Uma das principais formas de se avaliarem a reputação de um pesquisador e a relevância de suas pesquisas é por meio do volume e impacto de suas publicações em revistas indexadas. Esse sistema de produção e divulgação da ciência tem funcionado com considerável eficiência, levando-se em conta que os resultados das pesquisas têm sido divulgados amplamente e com rapidez devido ao peculiar sistema de incentivos presentes na atividade científica, entre eles, o reconhecimento da originalidade. A lógica desse 
sistema é o assunto da segunda seção deste artigo. A terceira seção trata das argumentações teóricas por trás do financiamento público da ciência, predominante em grande parte do século XX. As críticas às patentes de universidades são apresentadas na quarta seção. As motivaçôes e os possíveis benefícios gerados pelas patentes de universidades são debatidos na quinta seção. Os resultados de um survey sobre a transferência de tecnologia de universidades e institutos públicos de pesquisa no Brasil e a importância das patentes neste processo são discutidos na sexta seção. Por fim, apresenta-se a conclusão, na forma de um balanço das críticas e dos benefícios.

\section{0 "ethos da ciência" e a lógica da produção de conhecimentos científicos}

A sociologia da ciência tem como um dos seus temas principais a explicação da ciência como um corpo de conhecimentos passíveis de constante avaliação, cujo progresso é um processo cumulativo que depende de divulgação ampla e ágil dos novos achados, de forma a serem rapidamente descartados se não forem confiáveis, ou confirmados e adicionados ao estado da arte. O sociólogo norte-americano Robert Merton (1974) expôs um conjunto complexo de normas e valores que caracterizam o que ele chama de "ethos da ciência" e constituem uma "obrigação moral para o cientista”, servindo de base para explicar a lógica da produção de conhecimentos científicos.

Merton (1974, p. 41) lista quatro imperativos institucionais que compõem o ethos da ciência moderna: universalismo, comunismo, ${ }^{1}$ desinteresse e ceticismo organizado. O universalismo diz respeito à norma sob a qual os conhecimentos gerados, com pretensões de serem verdades, devem ser submetidos a avaliação por critérios impessoais. "A aceitação ou a rejeição dos pedidos de ingresso nos registros da ciência não devem depender dos atributos pessoais ou sociais do requerente; não têm importância em si mesmas a raça, a nacionalidade, a religião e as qualidades de classe ou pessoais" (MERTON, 1974, p. 41). A norma do comunismo reconhece a ideia da cumulatividade da produção científica, apontando que "as descobertas substanciais da ciência são produto da colaboração social e estão destinadas à comunidade. Constituem herança comum em que os lucros do produtor individual são severamente limitados" (MERTON, 1974, p. 45). O desinteresse, que não se confunde com a falta de motivação, marca o cientista como sendo um ator social

1. Também tratado como comunalismo. 
que é recompensado por agir de forma a parecer altruísta, não procurando obter recompensas monetárias pelo seu trabalho. Um dos principais objetivos do pesquisador é estabelecer a prioridade da descoberta e sua recompensa seria o reconhecimento, pelos pares, por suas contribuições originais (MERTON, 1957, apud STEPHAN, 1996, p. 1.201). O ceticismo organizado impõe ao conhecimento gerado um teste rigoroso e imparcial. Esses imperativos institucionais em conjunto colocam a ciência como uma atividade que possui um nível de respeito e credibilidade dificilmente alcançado em outros ramos de atividade.

Essa concepção da atividade de produção científica, em que os imperativos institucionais servem como balizadores da forma como os cientistas geram e divulgam conhecimentos, é claramente uma concepção ideal, mas talvez não muito longe da realidade. Embora se saiba que muitos cientistas importam-se com recompensas financeiras pelo seu trabalho, mantenham por um período seus resultados em segredo para obterem algum ganho ou o reconhecimento da prioridade em "disputas ou corridas pela prioridade" (DASGUPTA; DAVID, 1994) e que as formas de avaliar o conhecimento gerado não são desprovidas de falhas, a atividade científica, quando comparada a outras, possui uma reputação de destaque ano que se refere à credibilidade. Merton (1974, p. 50) lembra que:

(...) as atividades dos cientistas estão submetidas a um policiamento rigoroso, sem paralelo, talvez, em qualquer outro campo de atividade (...) O cientista não lida com uma clientela leiga, como o fazem o médico e o advogado. A possibilidade de explorar a credulidade, a ignorância ou a necessidade do leigo está assim consideravelmente reduzida. A fraude, a chicana e as pretensōes irresponsáveis (charlatanismo) são ainda menos prováveis do que entre as profissóes de "serviço".

Essas características que tornam o conhecimento científico aberto à sociedade, em especial aos pares, fazem com que o sistema seja eficiente, no sentido de agilizar a validação dos achados e reduzir a ocorrência de esforços duplicados (DAVID, 2003).

Qualquer fator que interferisse nos imperativos institucionais afetaria a condução ideal da atividade científica. Seguindo essa lógica, ao patentear algum conhecimento, o cientista estaria deixando de lado o comunismo e o desinteresse. David (2003) aponta alguns exemplos de como o patenteamento em áreas como as "ciências da vida" (incluindo bases de dados em bioinformática) poderia trazer problemas para o progresso da ciência: 
Isso [o patenteamento] eleva o custo não simplesmente da pesquisa direcionada à produção de um novo produto especifico (e.g., kits de testes de diagnósticos para uma classe particular de condiçôes geneticamente transmitidas), mas também da pesquisa exploratória que pode permitir a criação futura de várias aplicaçôes, incluindo aquelas que ainda nem são sonhadas. Usando a evocativa frase de um proeminente cientista Europeu, bases de dados de bioinformática montadas cooperativamente estão permitindo pesquisadores fazerem importantes descobertas no curso de "viagens não planejadas através do espaço da informaçãa". Se esse espaço se torna preenchido por um emaranhado de direitos de propriedade, então tais viagens de descoberta irão se tornar mais incômodas e mais caras de se realizar, descobertas não previstas se tornarão menos freqüentes e é provável que a taxa de expansão da base de conhecimento diminua (DAVID, 2003, p. 12-13). (tradução nossa).

Os trabalhos de Callon $(1994,1995)$ sobre a dinâmica do progresso científico, embora com argumentos ligeiramente distintos dos apresentados por Merton, destacam a necessidade da cooperação, do estabelecimento de redes de pesquisas e do livre acesso aos conhecimentos gerados para o bom funcionamento desse processo. Callon (1995) apresenta e analisa quatro modelos pelos quais o progresso científico poderia ser entendido: modelo da ciência como conhecimento racional, o qual procura diferenciar a ciência das outras formas de conhecimento; modelo da ciência como competição, que explora a forma organizacional da ciência, pela qual os pesquisadores interagem e competem entre si por reconhecimento; ciência como prática sociocultural que, fundamentalmente, não difere das outras atividades humanas; e ciência como "tradução estendida" de proposições teóricas, que são o objetivo principal da atividade científica. $\mathrm{O}$ autor descreve detalhadamente a natureza da produção científica em cada modelo, bem como os agentes envolvidos, sua dinâmica básica, como é formado o consenso, a organização social e o processo geral dessa atividade.

Embora esses modelos expliquem a atividade científica de formas diversas, todos apresentam, implícita ou explicitamente, o argumento de que o progresso científico requer que o conhecimento gerado seja de livre acesso para ser avaliado em um debate aberto. Para o autor, a ciência é uma fonte de variedade "e essa variedade depende da diversidade de interesses e projetos que estão incluídos nos coletivos que reconfiguram a natureza e a sociedade" (CALLON, 1994, p. 417). (tradução nossa). Como uma prática sociocultural -, ou seja, dinâmica em sua essência -, a atividade científica pode até evoluir em seus preceitos e valores de forma a contornar os efeitos negativos decorrentes da crescente tendência de patenteamento de conhecimentos científicos. Contudo, mesmo que isso possa vir a ocorrer, no curto 
prazo ainda existem chances de que vários progressos científicos possam ser afetados pela dificuldade de acesso à informação imposta por alguma patente.

O conflito vivido atualmente dentro da própria lógica da produção de conhecimentos científicos está ligado ao fato de que várias áreas científicas, como a biotecnologia, que dependeram de um amplo acesso aos conhecimentos previamente gerados para sua evolução recente, também estão crescentemente patenteando esses conhecimentos. Os efeitos para o progresso dessas áreas são difíceis de serem previstos, mas um exemplo das pesquisas recentes na área de física de partículas pode dar uma ideia de como o acesso à informação é cada vez mais importante, levando à formação de redes mundiais de pesquisa. Na década de 1970, apenas algumas dezenas de pesquisadores tinham acesso à base de dados do Fermilab. ${ }^{2} \mathrm{O}$ avanço das tecnologias de informação e comunicação possibilitou a milhares de pesquisadores do mundo o acesso a essa base, aumentando consideravelmente a chance de surgirem novos avanços científicos.

\section{Modelo linear, falhas de mercado e a lógica da produção pública de ciência}

A importância da ciência ganhou maior destaque após a Segunda Guerra Mundial. O grande volume de recursos públicos destinados à pesquisa nos EUA e os avanços resultantes, tais como a penicilina, o radar e o principal resultado do Projeto Manhattan, a bomba atômica, evidenciaram o poder da ciência nos rumos políticos e econômicos da humanidade. Vários países, reconhecendo essa importância, passaram a criar conselhos de pesquisa (como a National Science Foundation, em 1950, nos EUA, e o CNPq, em 1951, no Brasil³), instituições científicas e laboratórios nacionais de pesquisa. Essas organizações foram influenciadas pela visão de um modelo linear de ciência e tecnologia (FREEMAN; SOETE, 1997, p. 300), segundo o qual aplicar fundos públicos em pesquisas ${ }^{4}$ era justificável, pois o aumento do conhecimento

2 O Fermi National Accelerator Laboratory, localizado no estado de Illinois (EUA), possui um dos maiores aceleradores de partículas do mundo. A cada experimento é gerado um volume de dados que é impossível de ser analisado por um grupo pequeno de pesquisadores.

3 Praticamente todas as instituições públicas de fomento à pesquisa científica criadas após a Segunda Guerra Mundial foram influenciadas pelo famoso relatório de Vannevar Bush, Science: The Endless Frontier, escrito em 1945, que deu origem à formação da National Science Foundation (NSF) em 1950. Em uma carta encaminhada, juntamente ao relatório, para o presidente Roosevelt, Bush argumentou que "o progresso científico é fator essencial para a nossa segurança como uma nação, nossa melhor saúde, mais empregos, para um maior padrão de vida e para nosso progresso cultural" (BUSH, 1945). (tradução nossa).

4 Fossem elas pesquisas básicas (com o objetivo de compreender os fundamentos de algum fenômeno) ou aplicadas (direcionadas à resolução de problemas). Para uma discussão das dificuldades em se diferenciar a pesquisa básica da aplicada, ver Rosenberg (1982). 
científico levaria a inovações e, consequentemente, ao desenvolvimento econômico. Mesmo tendo uma base teórica limitada, por não considerar a complexidade presente na relação entre ciência e tecnologia, ${ }^{5}$ a ideia por trás desse modelo exerceu grande influência em vários países. Pode-se chamar esse fato de "influência política do modelo linear".

Do lado teórico da explicação dos gastos públicos em ciência, destacam-se os trabalhos de Arrow (1962) e Nelson (1959), que contribuíram para a compreensão das implicações econômicas a respeito do fato de que a geração de conhecimento científico depende de um sistema de recompensa que não é baseado no mercado. O mercado falha em resolver os problemas de alocação de recursos para a produção de conhecimento em razão das características particulares da informação. ${ }^{6}$

Arrow (1962) discute a impossibilidade da alocação ótima de recursos para a atividade inventiva em mercados competitivos devido ao risco presente nesta atividade e às "características especiais" da mercadoria "informação". A geração da informação, por meio da pesquisa e da invenção, é uma atividade permeada pela incerteza, ou seja, não é possível prever com exatidão o seu resultado (a informação gerada) a partir de seus insumos (pesquisadores, laboratórios, etc.) (ARROW, 1962, p. 172). Além disso, o custo marginal de utilização da informação é praticamente nulo, o que lhe confere uma característica de bem público. O conhecimento pode ser usado ao mesmo tempo por vários agentes sem se desgastar e é difícil excluir alguém do seu uso. Segundo Arrow, as empresas não possuem incentivos para realização de pesquisa básica porque a informação gerada é uma "mercadoria intangível" e de difícil apropriação. Como se trata de uma atividade que gera substanciais economias externas (no sentido de que o benefício social marginal é maior do que o benefício privado marginal), seria desejável que o governo financiasse pesquisas para geração de conhecimentos.

Resultados semelhantes também são discutidos em Nelson (1959). O próprio autor, em um artigo de reflexão sobre o seu estudo de 1959, reconhece que Arrow e ele estavam olhando o problema através das "lentes da teoria das falhas de mercado"

5 Rosenberg (1982) mostra, por meio de vários exemplos, que os avanços tecnológicos também influenciam a agenda de pesquisa científica. Para uma crítica ao modelo linear, ver Kline e Rosenberg (1986).

6 É importante destacar a distinção entre conhecimento tácito e conhecimento codificável (informação). Segundo Ashein e Gertler (2005, p. 293), o conhecimento tácito é difícil de ser codificado. Sua transmissão é feita com maior facilidade por contatos face-a-face, em que os agentes envolvidos estão imersos em um mesmo ambiente institucional, possuem a mesma linguagem e utilizam códigos de comunicação semelhantes, compartilham das mesmas normas de conduta e possuem um histórico de colaborações e interações informais. Já a informação, por ser codificável, pode ser transmitida com maior facilidade entre os agentes, mesmo quando não estão próximos. Contudo, é necessário que o receptor da informação possua capacidade de absorvê-la. 
e deixando de lado uma complexa estrutura institucional associada ao avanço da ciência (NELSON, 2006). No entanto, foi a visão da falha de mercado que se tornou a principal justificativa teórica dos economistas para os investimentos públicos em pesquisas acadêmicas, na segunda metade do século XX.

Com um respaldo teórico e tendo alcançado a simpatia dos formuladores de políticas de ciência e tecnologia, é válido questionar: a pesquisa científica financiada por fundos públicos tem contribuído para a geração de inovações tecnológicas? Estudos recentes mostram que sim. Narin et al. (1997) fornecem evidências empíricas da crescente importância da ciência pública ${ }^{7}$ para as inovações tecnológicas, por meio da análise das citações das patentes nos Estados Unidos nos períodos 1987-88 e 1993-94. Os dados indicam que a ciência pública é responsável por 73,3\% dos artigos citados pelas patentes industriais dos Estados Unidos, ou seja, a maior parte da base científica da indústria americana provém da ciência pública (NARIN et al. 1997, p. 328). ${ }^{8}$ Toole (2000) analisa a relação entre a pesquisa básica financiada por recursos públicos e a inovação na indústria farmacêutica dos EUA, no período 1978-1994. O autor calcula que um aumento de $1 \%$ no estoque de pesquisa básica leva a um crescimento entre $2 \%$ e $2,4 \%$ do número de medicamentos.

\section{A "privatização" da ciência pública: críticas às patentes de universidades}

Dada a justificativa teórica para o investimento de fundos públicos em pesquisa e a confirmação de estudos de que essas pesquisas são importantes para o avanço tecnológico, parece contraditória a atual tendência das universidades de "privatizar" o conhecimento gerado por meio de recursos públicos. Nelson (1992) chama a atenção para o fato de que privatizar o que não deve deixar de ser público no conhecimento tecnológico pode afetar a eficácia do sistema nacional de inovação norte-americano. Para o autor, tentar fazer as universidades parecidas com laboratórios industriais tenderá a desviar sua atenção de suas mais importantes funções: servir de fonte de novos conhecimentos tecnológicos e ser o veículo mais efetivo da sociedade em tornar público este tipo de conhecimento.

$\mathrm{O}$ autor desenvolve seu argumento em um trabalho posterior (NELSON, 2004), apontando que os resultados de pesquisas científicas quase nunca são pro-

7 Para os autores, "ciência pública" é a pesquisa científica realizada não só nas universidades, mas também nas instituições de pesquisa governamentais e financiadas por agências governamentais e filantrópicas.

8 Uma importante crítica a essa abordagem é feita por Pavitt (1991), em que o autor ressalta que parte da tecnologia gerada não é patenteada e essa tecnologia pode não ser tão dependente da ciência, mas sim das habilidades em engenharia e do "design cumulativo". 
dutos finais, acabados, prontos para o uso industrial. Esses resultados são utilizados em pesquisas adicionais. O que se tem observado é o aumento do patenteamento de técnicas de pesquisa. Patentear tais resultados e licenciar com exclusividade para uma empresa pode dificultar a realização de pesquisas futuras e a descoberta de usos alternativos, pois dificilmente uma única empresa consegue vislumbrar inteiramente o potencial de um dado conhecimento tecnológico. ${ }^{9}$ Exemplo disso são as várias aplicaçóes do laser descobertas por pesquisadores e empresas distintas, embora o princípio tecnológico fosse o mesmo.

Dessa forma, existem incertezas sobre os vários caminhos que um conhecimento tecnológico poderia percorrer, sendo necessário manter, sempre que possível, os resultados científicos no domínio público. Assim, "privatizar o conhecimento básico é um perigo para o avanço tanto da ciência quanto da tecnologia” (NELSON, 2004, p. 456). (tradução nossa).

Para avaliar o alcance dessa crítica é importante questionar que tipo de invenção tem sido objeto de patenteamento por parte das universidades. No Brasil, por exemplo, as tecnologias patenteadas pelas universidades são significativamente distintas do padrão observado para o total do país (PÓVOA, 2008). Os tipos de tecnologia ${ }^{10}$ para os quais as universidades mais realizaram depósitos de patentes, entre 1979 e 2003, foram análise-mensuração-controle (14,2\% do total), ${ }^{11}$ química orgânica $(9,3 \%)$, biotecnologia $(7,5 \%)$, farmacêuticos-cosméticos $(7,4 \%)$ e engenharia médica $(6,8 \%)$. Ou seja, as universidades estão produzindo depósitos de patentes relacionados a setores industriais de grande intensidade tecnológica. Comparando os dados de pedidos de patentes de universidades com os de residentes no Brasil ${ }^{12}$ (entre 1998 e 2001), verifica-se que, embora as universidades tenham realizado uma média de apenas $1 \%$ do total dos depósitos de patentes de residentes no país, a desagregação dos dados por tipos de tecnologias mostram que elas foram responsáveis por $34,5 \%$ dos depósitos na área de biotecnologia e $28,6 \%$ na de química orgânica,

9 "Na área de células-tronco, por exemplo, patentes foram concedidas em estágios prematuros demais; e ocorreram licenciamentos exclusivos, o que não deveria ter ocorrido. Nesse caso, as decisões impediram o progresso da ciência, ao invés de ajudá-lo" (Jon Sandellin, vice-presidente da Association of University Technology Managers - AUTM, em entrevista ao Boletim Inovação da Unicamp). Disponível em: <http://www.inovacao.unicamp.br/report/entre-sandelin. shtml>. Acesso em: novembro de 2007.

10 As classificações estão baseadas na metodologia do Observatoire des Sciences e des Techniques - OST (OST, 2001), que visa agregar e simplificar as informações contidas na Classificação Internacional de Patentes.

11 Esse percentual refere-se ao total de depósitos com informações disponíveis sobre a classe tecnológica à qual pertence. Foram obtidas informações para 921 depósitos. Considerando-se o total de depósitos de patentes do país, as tecnologias mais patenteadas foram aquelas relacionadas ao "consumo das famílias".

12 Dados extraídos de Landi (2005), tabela anexa 6.13. As diferenças de períodos são devidas à disponibilidade de dados. 
nesse período. Esses dados sugerem uma contribuição significativa das universidades para invençôes em áreas baseadas intensamente na ciência. Entretanto, em sua grande parte, os conhecimentos tecnológicos patenteados nessas áreas são gerais, servindo para diversas aplicaçôes, como instrumentos que servem para pesquisas subsequentes.

Outra crítica às patentes de universidades está relacionada ao processo de gerenciamento dos licenciamentos. Trabalhos recentes baseados em dados sobre transferências de tecnologia ocorridas nos EUA têm mostrado que, mesmo quando a universidade decide patentear, a tarefa não é fácil. Apesar dos números agregados animadores, ${ }^{13}$ vários são os escritórios de transferência de tecnologia (ETT) que não conseguem se manter financeiramente. Em uma entrevista, Jon Sandellin, vice-presidente da Association of University Technology Managers (AUTM) por duas vezes, quando questionado sobre a rentabilidade dos licenciamentos para as universidades, afirmou que "apenas 10\% das universidades são responsáveis por mais de $90 \%$ da receita de royalties. As universidades entre as $15 \%$ que recebem menos não têm, seguramente, nenhum lucro". ${ }^{14}$ Um dos fatores para isso é que muitas invençôes levam tempo para gerar receitas para as universidades e muitos desses escritórios de transferência são recentes. Também deve-se considerar o fato de que o sucesso dos escritórios depende de um conjunto de aptidóes e talentos (como um profundo conhecimento do campo técnico e das aplicaçóes industriais, bem como de negociações de contratos complexos com as empresas), que não são abundantes entre os administradores das universidades (MOWERY et al. 2004). Além disso, mesmo nas principais universidades dos EUA, a maior parte das receitas com licenciamento provém de um grupo pequeno de invenções relacionadas a áreas que tradicionalmente dão mais importância à patente como mecanismo de apropriação dos ganhos provenientes das invençôes, como fármacos (MOWERY et al., 2001).

Como uma das críticas às patentes de universidades, acrescenta-se o fato de que muitas universidades incluíram no rol de argumentos da qualidade de sua pesquisa o número de patentes que possui. Isso se torna perigoso na medida em que parte significativa da pesquisa acadêmica está relacionada a áreas da ciência que não geram conhecimentos patenteáveis. Mesmo dentro da universidade, um departamento de física tende a gerar menos patentes do que o de engenharia mecânica. Nem por isso a pesquisa realizada no primeiro é de menor qualidade e importância. Muitas

\footnotetext{
13"Para as 84 instituições dos EUA que responderam às pesquisas de 1991 e 2000 da Association of University Tecnology Managers (AUTM), "o número de invenções cresceu 84\%, a solicitação de novas patentes em $238 \%$, os acordos de licenciamento em 161\%, e os royalties em mais de 520\%". Disponível em: <http://www.inovacao.unicamp.br/ report/inte-science.shtml>. Acesso em: novembro de 2007.

14 Disponível em: <http://www.inovacao.unicamp.br/report/entre-sandelin.shtml>
} 
vezes, a pesquisa realizada em física serve de base para a geração de conhecimentos tecnológicos e patentes na área de engenharia mecânica.

Por fim, existem críticas relacionadas à mudança da cultura e da agenda de pesquisa das universidades. Com relação à agenda, poderia haver um movimento tendente a se concentrar em temas que gerassem mais patentes, afastando a universidade da ciência básica em direção à ciência aplicada. Contudo, essa é uma crítica que tem alcançado pouca, ou nenhuma, validação empírica (MOWERY et al. 2001; 2002). Rafferty (2008), por exemplo, faz um estudo econométrico sobre as atividades de pesquisa e desenvolvimento realizadas nas universidades dos EUA para testar a hipótese de que o Bayh-Dole Act poderia levar as universidades a fazer mais pesquisas aplicadas em detrimento das básicas. $\mathrm{O}$ autor mostra, a partir de dados sobre financiamentos de projetos acadêmicos de $\mathrm{P} \& \mathrm{D}$, que não há evidências de que o Bayh-Dole Act tenha alterado o comportamento das universidades.

Já alguns aspectos da cultura das universidades, como a divulgação rápida dos resultados, podem ser afetados se o pesquisador preferir retardar a publicação até realizar o pedido da patente. De fato, algumas defesas de tese de doutorado estão deixando de ter seu caráter de ato público para se realizarem "a portas fechadas" e com compromisso escrito dos membros da banca examinadora de não divulgar os resultados a que tiverem acesso.

Do lado das indústrias também surgem críticas ao comportamento pró-patente das universidades, ao argumentarem que estão pagando impostos que servem para financiar a pesquisa e ainda têm que pagar para ter acesso à tecnologia. Também existe uma preocupação de indústrias relacionadas a algumas áreas, como a biotecnologia, de que as patentes de universidades dificultam ainda mais o processo de desenvolvimento tecnológico, o qual, nesse tipo de indústria, depende de informaçôes tecnológicas patenteadas pertencentes a diferentes titulares. Isso torna ainda mais oneroso o processo de licenciamento (MOWERY et al. 2004).

Muitas dessas críticas não são recentes. Allan Gregg, diretor da Fundação Rockefeller por 37 anos, abordou o crescente envolvimento das universidades na questão do patenteamento e expôs casos interessantes na edição de março de 1933 da revista Science, mostrando preocupaçôes nos EUA já na década de $1930 .{ }^{15}$

15 "No estado fictício de 'Todo Lugar' - lá se produz leite - conheço o dono de uma grande companhia de laticínios. Ele está irado: a Associação dos Pesquisadores da Universidade de Todo Lugar patenteou um processo que poderia melhorar o valor nutritivo de certos produtos do leite. Ele diz: 'Pago impostos para apoiar a universidade e seus pesquisadores, e quando eles encontram alguma coisa que eu poderia usar, tenho de pagar de novo!' (...) Uma patente norte-americana bem conhecida para o tratamento de uma importante doença infecciosa é protegida num país do exterior por uma cláusula que proíbe seu uso em pesquisa que se dirija a seu aperfeiçoamento. Uma organização de pesquisa muito prestigiada naquele país buscou conselho legal para as prováveis consequências de usar o material com propósitos de pesquisa; recebeu a informação de que um julgamento custaria mais de US\$ 15 mil. Não tendo fundos para lutar pelo direito legal de realizar a pesquisa, eles se retiraram e deixaram o campo 


\section{Motivações para patentear}

O Bayh-Dole Act partiu da premissa de que a universidade seria uma fonte de novas invenções com potencial para a comercialização, sendo necessário o patenteamento para induzir e agilizar os investimentos industriais para realizar esse potencial. Assim, na ausência de patentes, muitas invençôes acadêmicas correm o risco de permanecerem inexploradas.

O estudo de Mazzoleni e Nelson (1998) a respeito das teorias econômicas sobre os benefícios e custos das patentes ajuda a compreender a base teórica na qual o Bayh-Dole Act se apoiou. Os autores apresentam quatro teorias, não mutuamente excludentes, que explicam o propósito da existência de patentes. A primeira trata a patente como um instrumento de incentivo ao surgimento de invençôes, com base na concessão de um monopólio temporário para que o inventor possa obter retornos que compensem seus gastos com o processo inventivo. De acordo com a segunda teoria, como a patente exige que seja feita uma descrição detalhada da invenção, ela induz os inventores a revelar e disseminar suas invençôes. Para a terceira teoria, que segundo os autores serviu como uma das bases para discussão e aprovação do Bayh-Dole Act, a patente age como um indutor dos investimentos necessários para que a invenção seja desenvolvida e comercializada. Essa teoria torna-se interessante quando são analisados contextos como os das universidades, que possuem capacidade para gerar invenções, mas muitas vezes não têm condições (ou interesse) de realizar o trabalho de desenvolvimento e comercialização. Nesse sentido, as universidades deveriam patentear suas invenções, pois uma empresa provavelmente só investirá no desenvolvimento de uma invenção acadêmica se puder ter o controle sobre os direitos de propriedade (por meio de um licenciamento, por exemplo) da inovação que se seguirá. Por fim, de acordo com a quarta teoria, a patente permite ao seu detentor um controle ordenado da exploração das possibilidades abertas pela invenção. ${ }^{16}$

\footnotetext{
livre para o patenteador. O único consolo que pode ser oferecido a eles é que os pesquisadores não perderão seu tempo no banco das testemunhas - um desperdício de tempo que já desgostou pelo menos um cientista neste país a ponto de ele deixar uma área de pesquisa na qual processos poderiam vir a requerer seu tempo. $O$ reitor de uma das nossas maiores escolas médicas reclama que um de seus professores está tão ocupado controlando o produto feito sob a patente detida pela universidade que não the sobra tempo para pesquisar ou lecionar. Por ser um interesse da universidade, não pode ser descuidado, uma vez que pode render algum dinheiro; desta forma, um pesquisador competente agora está ocupado testando um produto comercial. Enquanto existir uma chance de que o produto possa ser melhorado por outra pessoa, é provável que ele fique preso por algum tempo a este único assunto" (GREEG, 1933, p. 258). Para mais detalhes e acesso ao texto traduzido da Science, ver edição de 19 de dezembro de 2005 do Boletim Inovação Unicamp, disponível em <http://www.inovacao.unicamp.br/report/ inteesp-patentes-universidades.shtml>. Acesso em: outubro de 2007.

16 Os próprios autores destacam que a patente é apenas um dos mecanismos de apropriação dos resultados do esforço inovativo e que em vários setores industriais a patente não é necessária para induzir o desenvolvimento das invenções, podendo prevalecer, por exemplo, o segredo industrial.
} 
Uma das questōes que motivam o patenteamento é a preocupação em garantir que os benefícios decorrentes da invenção possam ser apropriados de alguma forma pela universidade e pela sociedade. Possuindo o direito de propriedade sobre a invenção, a universidade pode controlar seu uso por parte das empresas e impedir que o conhecimento seja apropriado e explorado por uma única empresa, o que está em sintonia com a quarta teoria descrita por Mazzoleni e Nelson (1998).

Nessas motivações, a preocupação principal é garantir que as invenções possam ser comercializadas, mas de forma a beneficiar a universidade e a sociedade, ou seja, sem que se constitua um monopólio fora do controle da universidade. $\mathrm{O}$ inventor passa a ter também um controle sobre a sua invenção, podendo impedir que a mesma seja utilizada de forma indevida por alguma empresa.

Jensen e Thursby (2001) apresentam resultados de uma pesquisa em que a maior parte das invençōes de universidades, quando licenciadas, é do tipo "provas de conceito" ${ }^{17}$ Além disso, $71 \%$ das invenções licenciadas requerem cooperação entre inventor e a empresa para que se tenha sucesso na comercialização. 'Ninguém sabe o seu potencial comercial porque elas [invençôes acadêmicas] estão em um estágio muito inicial de desenvolvimento. $\mathrm{Na}$ verdade, elas são tão embrionárias que é necessário um esforço de desenvolvimento por parte do inventor para que haja uma chance razoável de sucesso comercial" (JENSEN; e THURSBY, 2001, p. 241). (tradução nossa).

Os autores elaboram um modelo no qual a remuneração do inventor decorrente do licenciamento pode se dar por meio de dois esquemas: recebimento de taxas ou fundos para pesquisa; ou pagamentos atrelados à comercialização do produto, como royalties. Partindo da hipótese de que invençôes com chance mínima de sucesso têm sua probabilidade de sucesso acrescida com o esforço do inventor, os autores mostram que a adoção de esquemas envolvendo royalties são mais eficientes para gerar o sucesso da invenção, por resolverem um problema de risco moral, atrelando o esforço do pesquisador aos resultados da comercialização.

É possível destacar também uma motivação defensiva. Como exemplo, o governo brasileiro, ao regulamentar a obtenção de royalties decorrentes de direitos de propriedade intelectual por parte de pesquisadores de universidades e institutos de pesquisa, pontuou entre os objetivos, “(...) evitar a evasão de conhecimentos e de inventos gerados nos institutos". ${ }^{18}$ Segundo o relato de um pesquisador da Uni-

\footnotetext{
17 Demonstração inicial de que um método, ou teoria, é viável ou plausível.

18 Ver o documento assinado pelo então ministro da Ciência e Tecnologia, José Israel Vargas, "Royalties para pesquisadores dos institutos de pesquisas e das universidades do país", disponível em: <http://www.radiobras.gov.br/ct/ artigos/1998/artigo_080598.htm>. Acesso em: janeiro de 2008.
} 
versidade Federal de Minas Gerais, um ano após ter apresentado o resultado de sua pesquisa em uma conferência internacional, descobriu, na mesma conferência do ano seguinte, que uma empresa estrangeira havia concebido um produto baseado em seus resultados. O pesquisador alegou que agora está dando maior atenção às patentes para evitar que isso aconteça novamente.

No caso do Brasil, em que grande parte das empresas não realiza $P \& D$ interno contínuo, não possuindo, dessa forma, capacidade de monitorar o que está sendo produzido de conhecimento relevante para sua área, a patente da universidade pode ter um efeito indutor da comercialização, por servir como "propaganda" da invenção. Ao se permitir que a universidade obtenha receitas das licenças, surge um incentivo para que sejam criados escritórios de transferência de tecnologia, que estarão incumbidos de fazer um levantamento das invenções geradas na universidade, entrar em contato com o inventor para orientar e auxiliar no processo de patenteamento e procurar uma empresa disposta a licenciar a patente. Essa motivação difere daquela na qual se baseou o Bayh-Dole Act, pois serve de motivação para a universidade divulgar as invenções e procurar parceiros, enquanto no Bayh-Dole Act a patente serviria de incentivo para as empresas.

\section{Como as invenções acadêmicas fluem para as empresas?}

As universidades brasileiras alcançaram um lugar de destaque na questão de patentes nos últimos dez anos. Na lista dos 50 maiores depositantes de patentes no Brasil, entre 1999 e 2003, com prioridade brasileira, aparecem oito universidades (Unicamp, UFMG, USP, UFRJ, Unesp, UFRGS, UFPE e UFV), quatro institutos públicos de pesquisa (Embrapa, Fiocruz, IPT e CNEN) e duas agências de fomento ${ }^{19}$ (Fapesp e CNPq), ou seja, $24 \%$ dos depositantes. Além disso, o primeiro lugar nessa lista é ocupado por uma universidade (Unicamp). Em termos numéricos, de acordo com Dagnino e Silva (2009), as universidades realizaram 1.359 depósitos de patentes, entre 2001 e $2008,{ }^{20}$ contra 933 por parte das empresas. Dada a relevância das patentes acadêmicas no Brasil, é preciso buscar compreender como essas invenções fluem para as empresas.

Para entender a real importância das patentes no processo de transferência de tecnologia das universidades para as empresas, foi conduzido um survey endereçado

\footnotetext{
19 A maior parte dos depósitos das agências de fomento é em parceria com universidades e institutos de pesquisa.

20 Houve um crescimento significativo do número de depósitos de patentes de universidades após 2002. Para mais detalhes sobre esse crescimento, ver Póvoa (2008).
} 
aos líderes de grupos de pesquisas de universidades e institutos públicos de pesquisa (IPP) registrados no Diretório de Grupos de Pesquisa no Brasil - CNPq, censo de 2004, que declararam ter desenvolvido e transferido tecnologia para alguma empresa. ${ }^{21}$ Dos 969 questionários enviados aos 558 líderes de grupos de pesquisa (cada líder recebeu um questionário referente a cada transferência declarada), obteve-se resposta de 178 líderes (uma taxa de resposta de 31,9\%) referentes a 271 transferências (taxa de resposta de $28 \%$ ).

Como existem vários tipos de tecnologia e cada grupo pode ter transferido para seu parceiro mais de um tipo ao longo do seu relacionamento, foi dada aos líderes dos grupos a opção de registrar, no questionário, mais de um tipo de tecnologia transferida. Também foi dada ao líder do grupo a opção de reconsiderar seu relacionamento com o parceiro e, diante das opções de tipos de tecnologias oferecidas no questionário, marcar se foi realizada ou não uma transferência de tecnologia para o parceiro. Dado que nove líderes marcaram a opção "não foi uma tecnologia", obteve-se uma taxa de resposta ajustada de $27 \%$ dos questionários (262) e $31 \%$ dos grupos (173). Entre as limitações da base de dados, está o fato de que não é possível saber o tamanho da população grupos de pesquisa que se relacionam com empresas, pois o preenchimento no Diretório é opcional. Assim, não se sabe quantos grupos existentes não estão registrados na base do CNPq. Contudo, imagina-se que a maior parte dos grupos que realizam trabalhos importantes tem interesse em dar visibilidade aos seus atos e, portanto, os resultados a seguir servem como uma ilustração da transferência de tecnologia feita no Brasil.

O Gráfico 1 mostra os principais tipos de tecnologias desenvolvidas por grupos de pesquisas sediados em universidades e IPP para o setor produtivo no Brasil. De acordo com as declarações dos líderes, os principais tipos de tecnologias transferidas foram novos processos (apontados em 46,2\% das relações de transferência) e novas técnicas (45\%). Pelo fato de ser difícil diferenciar um processo de uma técnica, poderia se esperar que os líderes dos grupos marcassem ambos. Contudo, foi observada uma correlação negativa entre estas respostas. Ou seja, quem declarou ter transferido um novo processo, em geral, não mencionou ter transferido uma nova técnica. A transferência de novos produtos aparece apenas em terceiro lugar, com $29,4 \%$. Assim, embora as universidades e IPP possam contribuir para a geração de

21 Esta seção está baseada em Póvoa (2008). É importante destacar que as informações foram declaradas pelos pesquisadores, sendo possível que a percepção de um pesquisador do que é "transferência de tecnologia" seja diferente da percepção de outros. Feita essa consideração, deve-se atentar para o fato de que os dados tratam de tecnologias desenvolvidas pelo grupo, ou seja, um conhecimento novo e não simplesmente aquele contido em livros-textos. 
novos produtos para a economia, este não é o principal tipo de tecnologia gerada e transferida. Os resultados sugerem que as universidades e IPP têm menor propensão a gerar novos materiais e designs. O baixo percentual de transferências classificadas como um novo "design" já era esperado, pelo fato de ser um tipo de tecnologia desenvolvido a partir de um forte fluxo de interação entre produtor e usuário, o que é verificado principalmente em empresas.

\section{GRÁFICO 1}

Tipo de tecnologia desenvolvida e transferida 2008

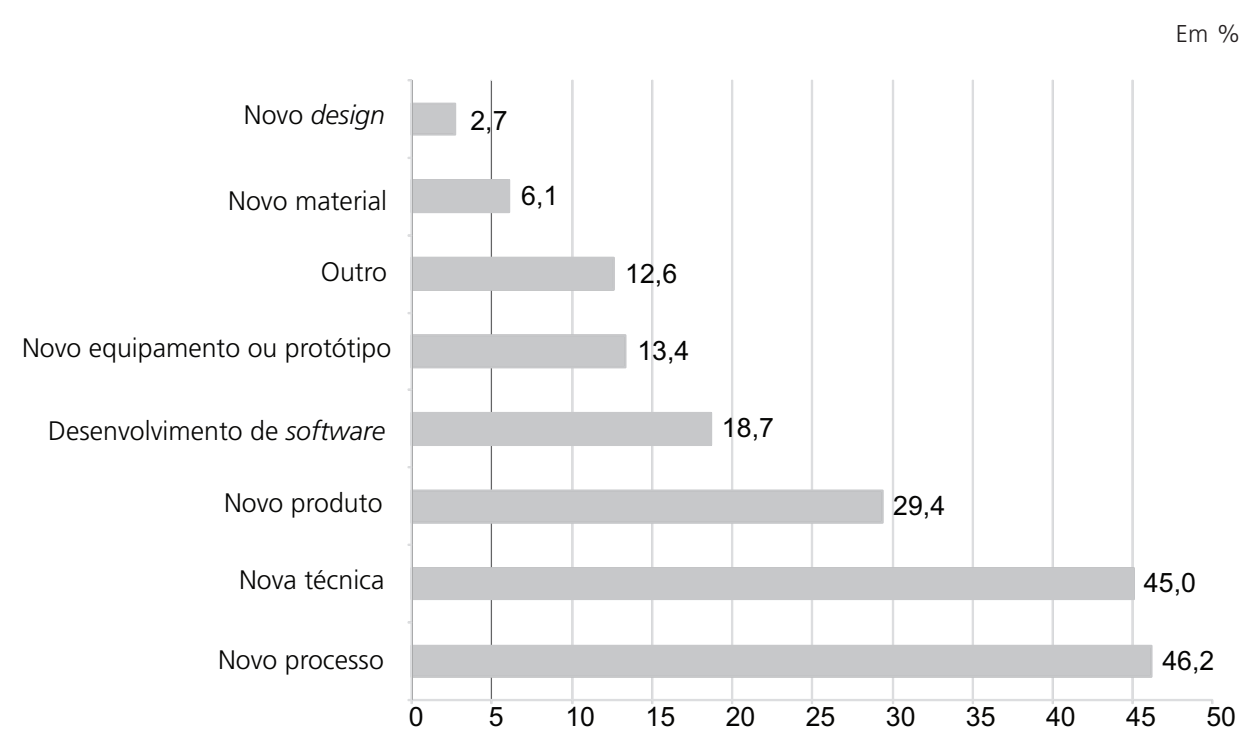

Fonte: Póvoa (2008).

Nota: Porcentagem de respondentes indicando o tipo de tecnologia desenvolvida e transferida ( $N=262$; erro padrão em parênteses).

Embora os grupos de pesquisa tenham utilizado vários tipos de mecanismos para a transferência de tecnologia, o principal foi, destacadamente, "publicaçóes e relatórios”, empregado em $74 \%$ das relações de transferência (Gráfico 2). Cerca de $45 \%$ utilizaram a "troca informal de informaçoes" e "treinamento de pessoal" e apenas $14,1 \%$ usaram "patente e licenciamento". Tal resultado sugere que a patente não é uma precondição para que haja uma relação na qual ocorra a transferência de tecnologia.

Esses resultados podem ser sumarizados da seguinte maneira: em primeiro lugar, destaca-se o alto percentual de transferências que utilizaram o mecanismo 
"publicaçōes e relatórios", colocando-o como o mecanismo primordial nas relações com o setor produtivo; em segundo lugar, está o fato de a contratação de estudantes ter sido apontada em um terço das relações de transferência, o que demonstra que o estudante é um canal singular de informações importante entre as universidades e IPP e as empresas, permitindo uma melhor sintonia do diálogo entre as partes; e, em terceiro lugar, destaca-se o baixo percentual de relaçôes que apontam as patentes como mecanismo de transferência.

\section{GRÁFICO 2}

\section{Mecanismos de transferência de tecnologia 2008}

Em \%

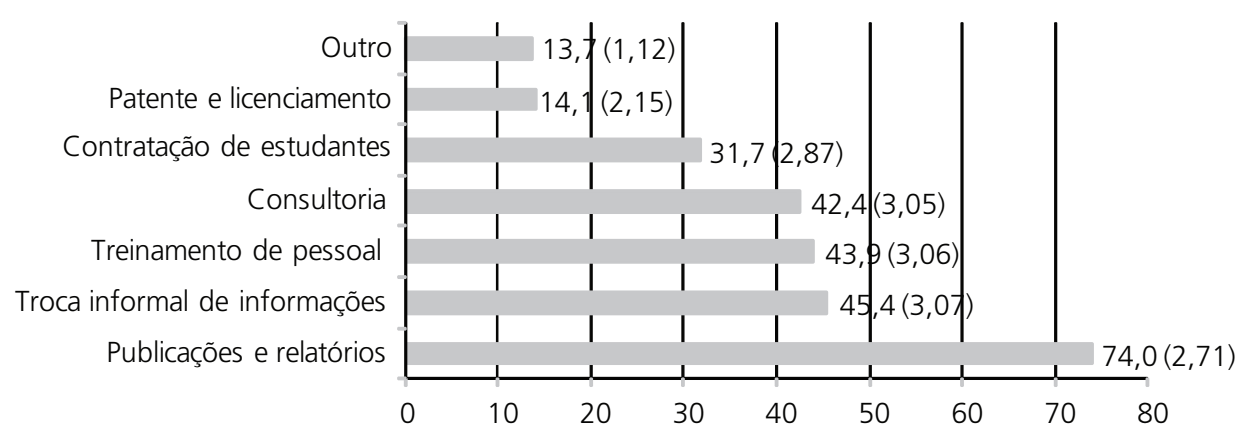

Fonte: Póvoa (2008).

Nota: Porcentagem de respondentes indicando o tipo de tecnologia desenvolvida e transferida ( $N=262$; erro padrão em parênteses).

Embora os resultados sugiram que a patente seja um mecanismo relativamente pouco utilizado, é preciso considerar que a importância de um mecanismo pode variar de acordo com o tipo de tecnologia transferida. Para avaliar essa questão, foram calculadas as correlaçóes entre os mecanismos e os tipos de tecnologia. ${ }^{22}$ Os resultados da Tabela 1, mesmo apresentando correlaçôes baixas, sugerem que tipos diferentes de tecnologias estão relacionados a mecanismos distintos. Enquanto a transferência de novos processos possui maior correlação com o mecanismo de treinamento de pessoal, a transferência de novos produtos, novos equipamentos e protótipos e novos materiais apresentam correlação maior com patentes.

Por que a patente parece ser mais importante para produtos, materiais e equipamentos ou protótipos do que para processos e técnicas? O estudo de Levin et al. (1987) sobre as formas de apropriação dos retornos do P\&D industrial 
ajuda a compreender a questão. Os autores mostram que as patentes de produtos são consideradas, pela indústria, mais efetivas para a apropriação dos retornos do que patentes de processos. Segundo os autores, existe uma tendência de considerar que o segredo industrial é mais efetivo para os novos processos tecnológicos. As empresas podem ter receio em patentear processos e ter que revelar detalhes de sua tecnologia. Já com relação a produtos, a lógica é inversa. As empresas querem divulgar as qualidades e aprimoramentos dos seus produtos para os consumidores, informação que acaba indo também para os concorrentes (LEVIN et al. 1987). Assim, as empresas tendem a patentear os produtos e manter processos em segredo. Esse argumento é corroborado pela baixa correlação encontrada entre patentes e novos processos e técnicas.

TABELA 1

Matriz de correlação: mecanismos de transferência e tipos de tecnologia 2008

\begin{tabular}{l|c|c|c|c|c|c|c}
\hline \hline $\begin{array}{l}\text { Mecanismos de } \\
\text { transferência }\end{array}$ & $\begin{array}{c}\text { Novo } \\
\text { produto }\end{array}$ & $\begin{array}{c}\text { Novo } \\
\text { processo }\end{array}$ & $\begin{array}{c}\text { Nova } \\
\text { técnica }\end{array}$ & $\begin{array}{c}\text { Novo } \\
\text { design }\end{array}$ & $\begin{array}{c}\text { Novo equipa- } \\
\text { mento ou } \\
\text { protótipo }\end{array}$ & $\begin{array}{c}\text { Desenvol- } \\
\text { vimento } \\
\text { de software }\end{array}$ & $\begin{array}{c}\text { Novo } \\
\text { material }\end{array}$ \\
\hline $\begin{array}{l}\text { Patente e } \\
\text { licenciamento }\end{array}$ & 0,55 & 0,17 & $-0,32$ & 0,02 & 0,35 & $-0,15$ & 0,42 \\
$\begin{array}{l}\text { Publicações e } \\
\text { relatórios }\end{array}$ & $-0,07$ & 0,21 & 0,21 & $-0,49$ & $-0,05$ & 0,15 & 0,59 \\
$\begin{array}{l}\text { Troca informal de } \\
\text { informações }\end{array}$ & $-0,05$ & 0,02 & 0,10 & $-0,30$ & 0,04 & $-0,15$ & $-0,15$ \\
$\begin{array}{l}\text { Contratação de } \\
\text { estudantes }\end{array}$ & 0,09 & $-0,03$ & 0,11 & $-0,38$ & $-0,12$ & 0,16 & 0,11 \\
$\begin{array}{l}\text { Treinamento } \\
\begin{array}{l}\text { Consultoria } \\
\hline\end{array}\end{array}-0,07$ & 0,31 & 0,04 & $-0,26$ & $-0,34$ & 0,26 & $-0,22$ \\
\hline
\end{tabular}

Fonte: Povoa (2008).

As transferências de novas técnicas e novos equipamentos e protótipos parecem seguir dinâmicas opostas. Novas técnicas estão negativamente correlacionadas com patentes e positivamente correlacionadas com consultorias, verificando-se o contrário para novos equipamentos e protótipos. Já a transferência de um novo software apresenta maior correlação com treinamentos e consultorias.

Os resultados desse survey, considerando-se as limitações apresentadas anteriormente, contribuem para contextualizar o papel das patentes. Embora não seja uma 
das principais formas de os conhecimentos tecnológicos fluírem das universidades e instituições públicas de pesquisas para as empresas, a patente é relevante quando considerados os diferentes tipos de tecnologias que são transferidas, principalmente quando se trata de novos produtos, equipamentos ou protótipos.

\section{Conclusões}

Este artigo procurou apresentar argumentos que permitissem responder se a universidade deve patentear suas invençôes ou não.

Em primeiro lugar, foi discutida a lógica da produção científica, com base no trabalho de Merton (1974). Os quatro imperativos institucionais que compõem o ethos da ciência moderna (universalismo, comunismo, desinteresse e ceticismo organizado) ajudam a explicar como se dá essa lógica e porque a ciência alcançou uma credibilidade superior à de outras atividades. Ao patentear suas invençôes, os pesquisadores acadêmicos poderiam estar na contramão desse sistema, impedindo que uma avaliação crítica dos resultados de suas pesquisas seja realizada com maior rapidez.

O argumento do Bayh-Dole Act, embora vá contra a lógica acima descrita, está sustentado no fato de a maior parte das invençôes acadêmicas possuir um caráter embrionário. Assim, o patenteamento, além de contribuir para que várias invenções possam resultar em novos produtos e processos que, de outra forma, ficariam parados na "prateleira do laboratório" sem gerar benefícios para a sociedade, poderia diminuir o intervalo entre uma descoberta e a sua efetiva comercialização.

O problema, assim colocado, é um trade-off entre a divulgação científica com livre acesso para desenvolvê-la e a agilização do processo de comercialização das invenções. Quanto mais livre for o acesso aos resultados das pesquisas, mais lento tenderá a ser o processo de transformação das invenções em inovações, sendo menor o volume de invençôes acadêmicas comercializadas.

Considerando-se que o objetivo primordial da pesquisa acadêmica é o aumento do estoque de conhecimentos científicos da humanidade, esse trade-off penderia para o lado do livre acesso. Agora, diante do fato de que as universidades têm sido colocadas (e estão se encarando) como um agente de um sistema nacional de inovação capaz de contribuir para o desenvolvimento econômico por meio da interação com a indústria, o trade-off pende para a obtenção de patentes.

Encontrar uma situação que comporte esses dois lados da balança parece ser a melhor solução. Com base nas discussões teóricas e nos resultados do survey 
apresentados anteriormente, a solução deve considerar, pelo menos, os seguintes fatores:

- a patente não é necessária e nem suficiente para transferir muito dos conhecimentos tecnológicos gerados na universidade;

- alguns tipos de conhecimentos tecnológicos, como novos processos, possuem baixa correlação com o uso de patentes no processo de transferência;

- invenções "prontas para o uso" tendem a depender menos das patentes para serem efetivamente comercializadas do que aquelas que estão em um estágio embrionário;

- manter um "banco de patentes" da universidade pode demandar mais recursos da universidade do que gerar ganhos;

- patentear técnicas de pesquisa prejudica o avanço científico;

- contrato de licenciamento com exclusividade não é precondição para que haja sucesso na comercialização e pode retardar o surgimento de outros produtos que a empresa detentora da exclusividade não consegue vislumbrar ou não tem interesse em desenvolver.

Desta forma, uma das conclusões é que patentear uma invenção que não é uma técnica de pesquisa e que, de outra forma, acabaria sendo utilizada em processos industriais em um prazo razoável não seria necessário. Ao contrário, serviria apenas para gerar receitas para a universidade e inventores e, potencialmente, retardar o avanço das pesquisas.

Por outro lado, invenções em que seja do interesse social evitar que acabem sendo apropriadas e, posteriormente, patenteadas por empresas que possam impor preços abusivos aos consumidores, entre os quais pode estar o próprio governo, deveriam ser patenteadas e colocadas sob o controle da universidade (considerando-se que os objetivos da universidade estejam em consonância com os sociais).

Impedir que sejam concedidas patentes para as universidades não é uma solução, pois existem situações em que elas são necessárias. Além disso, como concluiu Fritz Machlup em um trabalho seminal sobre o sistema de patentes, caso não existissem, as patentes não deveriam ser criadas, mas, uma vez existindo, seria irresponsável aboli-las (MACHLUP, 1958, p. 80, apud ALBUQUERQUE, 1998, p. 59).

A dificuldade que se apresenta é distinguir, de forma objetiva, em que situação a invenção acadêmica se enquadra: na que a patente contribui para proteger os interesses sociais, ou naquela em que a patente serve apenas para gerar receita por meio de licenciamentos? Propor uma metodologia para distinguir essas situações não é uma alternativa eficiente, pois, sendo difícil criar uma metodologia que seja 
de aceitação inquestionável, surgirão processos legais para tentar provar que uma determinada invenção se enquadra em uma ou outra situação. Tais processos demandam tempo, o que acabará retardando o uso do conhecimento embutido na invenção, seja para a pesquisa, seja para a comercialização.

Este artigo sugere que o problema a ser questionado deve ser "como" a universidade deve patentear, e não "se deve" patentear. A resposta passa pela formulação dos contratos de licenciamento. Os argumentos de Nelson (2004), apresentados na quarta seção, ajudam a compreender que contratos de licenciamento exclusivos deveriam ser evitados, sempre que possível, quando se trata de invençôes acadêmicas relacionadas a técnicas ou ferramentas necessárias para pesquisas posteriores ou invenções cujas aplicações são diversas, em que uma única empresa seria incapaz de explorá-la em todas as suas possibilidades. Ou seja, ao licenciar uma patente, seria desejável, do ponto de vista do bem-estar da sociedade, que a universidade procurasse licenciar sem exclusividade, de forma a tornar a invenção disponível para o maior número de interessados possível. Somente depois de tentar este tipo de licenciamento e não encontrar interessados, a universidade deveria oferecer um contrato de exclusividade.

Além do estabelecimento desse tipo de contrato, seria desejável que as universidades concedessem uma "licença para pesquisa". Mowery et al. (2004) relatam que juízes dos EUA têm uma tradição de decidir em favor dos pesquisadores quando estes últimos usam patentes de indústrias unicamente para o avanço da pesquisa científica. Contudo, como as universidades agora estão patenteando suas invençôes e restringindo seu acesso, a indústria está pleiteando nos tribunais o direito de restringir o acesso às suas patentes, já que agora são concorrentes.

\section{Referências bibliográficas}

ALBUQUERQUE, E. Patentes de invenção de residentes no Brasil (1980-1995): uma investigação sobre a contribuição dos direitos de propriedade intelectual para a construção de um sistema nacional de inovação. Tese (Doutorado em Economia) - Instituto de Economia, Universidade Federal do Rio de Janeiro, 1998.

ARROW, K. Economic welfare and the allocation of resources for invention. In: NELSON, R.R. (Ed.). The rate and direction of inventive activity. Princeton (NJ): Princeton University Press, 1962. 
ASHEIM, B.; GERTLER, M. The geography of innovation. Regional innovation systems. In: FARGERBERG, J.; MOWERY, D.; NELSON, R. (Eds.)s The Oxford Handbook of Innovation. Oxford University Press, 2005.

BUSH, V. Science: the endless frontier. A report to the president by Vannevar Bush, director of the Office of scientific research and development. Washington, DC: U.S. Government Printing Office, 1945.

CALLON, M. Is Science a public good? Science, Technology, \& Human Values, v. 19, n. 4, p. 395-424. Aut. 1994.

Four models for the dynamics of Science. In: JASANOFF, S.; MARKLE, G.; PETERSEN, J.; PINCH, T. (Eds.). Handbook of science and technology studies. SAGE Publications, 1995, p. 29-63.

COHEN, W.; NELSON, R.; WALSH, J. Links and impacts: the influence of public research on industrial R\&D. Management Science, v. 48, n. 1, p. 1-23, Jan. 2002.

DAGNINO, R.; SILVA, R. B. As patentes das universidades públicas. Boletim de Economia \& Tecnologia, UFPR, ano 05, v. 18, 2009.

DASGUPTA, P.; DAVID, P. Toward a new economics of science. Research Policy, v. 23, n. 5, p. 487-521, Sept. 1994.

DAVID, P. The economic logic of "open science" and the balance between private property rights and the public domain in scientific data and information: a primer. Stanford, CA: Stanford Institute for Economic Policy Research-SIEPR, 2003 (Discussion paper, 02-30).

FREEMAN, C.; SOETE, L. The economics of industrial innovation. 3. ed. London: Pinter, 1997.

GREGG, A. University patents. Science, New Series, v. 77, p. 257-259, Mar. 1933. (Traduzido por Boletim Inovação Unicamp). Disponível em: <http://www.inovacao.unicamp.br/ report/UniversityPatents-TR.pdf>

JENSEN, R.; THURSBY, M. Proofs and prototypes for sale: the licensing of university inventions. American Economic Review, v. 91, n. 1, p. 240-259, Mar. 2001.

KLEVORICK, A.; LEVIN, R.; NELSON, R.; WINTER, S. On the sources and significance of interindustry differences in technological opportunities. Research Policy, v.24, n. 2, p. 185-205, Mar. 1995.

KLINE, S.; ROSENBERG, N. An overview of innovation. In: LANDAU, R.; ROSENBERG, N. (Eds.). The positive sum strategy: harnessing technology for economic growth. National Academy Press, 1986, p. 275-305. 
LANDI, F. R. (Coord.). Indicadores de ciência, tecnologia e inovação em São Paulo - 2004. São Paulo: Fapesp, 2005.

LEVIN, R.; KLEVORICK, A.; NELSON, R.; WINTER, S. Appropriating the returns from industrial research and development. Brookings Papers on Economic Activity, n. 3, Special Issue on Microeconomics, p. 783-831, 1987.

MACHLUP, F. An economic review of the patent system. Washington, DC: US Government Printing Office, 1958. (Study of the Subcommittee on Patents, Trademarks, and Copyrights of the Committee on the Judiciary, United States Senate, study, 15).

MAZZOLENI, R. University patents, R\&D competition, and social welfare. Economics of Innovation and New Technology, v. 14, n. 6, p. 499-515, 2005.

MAZZOLENI, R.; NELSON, R. The benefits and costs of strong patent protection: a contribution to the current debate. Research Policy, v. 27, n. 3, p. 273-284, July 1998.

MERTON, R. K. Priorities in scientific discovery: a chapter in the sociology of science. American Sociology Review, v. 22, n. 6, p. 635-659, 1957.

. Imperativos institucionais da ciência. In: DEUS, J. D. (Org.). A crítica da ciência: sociologia e ideologia da ciência. Rio de Janeiro: Zahar, 1974, p. 37-52.

MOWERY, D.; SAMPAT, B.; ZIEDONIS, A. Learning to patent: institutional experience, learning, and the characteristics of U.S. university patents after the Bayh-Dole act, 19811992. Management Science, v. 48, n. 1, p. 73-89, Jan. 2002.

MOWERY, D.; NELSON, R.; SAMPAT, B.; ZIEDONIS, A. The growth of patenting and licensing by U.S. universities: an assessment of the effects of the Bayh-Dole act of 1980. Research Policy, v. 30, n. 1, p. 99-119, Jan. 2001.

MOWERY, D.; NELSON, R.; SAMPAT, B.; ZIEDONIS, A. Ivory Tower and industrial innovation: university-industry technology transfer before and after the Bayh-Dole act in the United States. Stanford, CA.: Stanford Business Books, 2004.

NARIN, F; HAMILTON, K. S.; OLIVASTRO, D. The increasing linkage between US. technology and public science. Research Policy, v. 26, n. 3, p. 317-330, Oct. 1997.

NELSON, R. R. The simple economics of basic scientific research. Journal of Political Economy, v. 67, n. 3, p. 297-306, 1959.

. The market economy, and the scientific commons. Research Policy, v. 33, n.

3, p. 455-471, Apr. 2004.

. Reflections on "The Simple Economics of Basic Research": looking back and looking forwards. Pisa, Italy: Sant'Anna School of Advanced Studies/Laboratory of Economics and Management (LEM), 2006 (LEM papers series, 2006/20). 
. What is "commercial" and what is "public" about technology, and what should be? In: ROSENBERG, N.; LANDAU, R.; MOWERY, D. C. Technology and the wealth of Nations. Stanford, CA: Stanford University, 1992, p. 57-71.

OBSERVATOIRE DES SCIENCES ET DES TECHNIQUES (OST). Science \& technologie indicateurs: 2000. Paris: Economica, 2001.

PAVITT, K. What makes basic research economically useful? Research Policy, v. 20, n. 2, p. 109-119, Apr. 1991.

PÓVOA, L. M. C. Patentes de universidades e instituiçōes públicas de pesquisa e a transferência de tecnologia para empresas no Brasil. 153 f. Tese (Doutorado em Economia) - Cedeplar, Universidade Federal de Minas Gerais, 2008.

RAFFERTY, M. The Bayh-Dole Act and university research and development. Research Policy, v. 37, n. 1, p. 29-40, Feb. 2008.

ROSENBERG, N. Inside the black box: technology and economics. Cambridge: Cambridge University, 1982.

SAMPAT, B. Patenting and US academic research in the 20th century: the world before and after the Bayh-Dole. Research Policy, v. 35, n. 6, p. 772-789, Jul.2006.

STEPHAN, P. The economics of science. The Journal of Economic Literature, v. 34, n. 3, p, 1.199-1.235, Sep. 1996.

TOOLE, A. The impact of public basic research on industrial innovation: evidence from the pharmaceutical industry. Stanford, CA: Stanford Institute for Economic Policy ResearchSIEPR, 2000 (Discussion paper, 00-07).

ENDEREÇOS PARA CORRESPONDENCIA:

Luciano Martins Costa Póvoa - costapovoa@gmail.com

Universidade de Brasília, Instituto de Ciências Humanas, Departamento de Economia.

Campus Universitário Darcy Ribeiro

70919-970 - Asa Norte - Brasília (DF)

Tel.: (61) 31046704 